\title{
Ageing of resin from Pinus species assessed by Infrared Spectroscopy
}

\author{
Victòria Beltran ${ }^{1}$, Nati Salvadó*1, Salvador Butí ${ }^{1}$, Trinitat Pradell ${ }^{2}$ \\ 1. Dpt. d'Enginyeria Química. EPSEVG. Universitat Politècnica de Catalunya, Av. Víctor Balaguer s/n, 08800 Vilanova \\ i la Geltrú, Barcelona \\ 2. Dpt. Física. Universitat Politècnica de Catalunya. Campus del Baix Llobregat, c. Esteve Terradas 8, 08860 \\ Castelldefels, Barcelona \\ * Corresponding author: \\ E-mail address: nativitat.salvado@upc.edu \\ Telephone: 0034938967717 \\ Fax: 0034938967700
}

\section{Abstract}

Resins obtained from Pinus genus species have been widely used in very different fields throughout history. As soon as they are secreted molecular changes start altering their chemical, mechanical and optical properties. The ageing processes are complex and chemical and structural changes associated to resin degradation are not yet fully known. Many questions still remain open, for instance changes happening in pimaranes, one of the two diterpenoid constituents of the resin.

A systematic study of the ageing process of Pinus resins is done through of Fourier Transform Infrared Spectroscopy (FTIR) using chemical standards and complementing obtained results with Gas Chromatography coupled to Mass Spectrometry (GC/MS) analysis when necessary. Moreover, long-term degradation processes are also investigated through the analysis of a selection of dated historical resins. The study overcomes the limitations of GC/MS and brings new information about the reactions and interactions between molecules during Pinus resin ageing process, providing information about bonds affected and unaffected and can be used as specific markers of the degradation and of the resins themselves.

Keywords: diterpenic resin, IR spectroscopy, Pinus resin, ageing, abietanes, pimaranes

\section{Introduction}

The Pinus genus belongs to the Pinaceae family; this genus includes many species, mainly trees, found mostly in the north hemisphere [1]. One of the features of Pinus species is that they exudate a resinous secretion, known as rosin or colophony, which has chemical and physical properties adequate for many uses: printing inks, varnishes, adhesives, soaps, food additives... [2-4]. The first molecular changes can be observed after a few weeks after collecting the resin, consequently the identification of the oxidative pathways and how they 
affect the chemical composition is essential for the correct identification of the material, its degree degradation and to determine of the long-term resin degradation process.

Previous GC/MS analyses of Pinus resins have shown that fresh resin contains mainly two kinds of diterpenoid structures: abietanes and pimaranes. Abietic, palustric, laevopimaric and neoabietic acids are some of the unoxidized abietanes present in fresh resin, which tend to isomerize producing abietic acid. In atmospheric conditions, abietic acid evolves into more oxidized molecules [5-9], the most oxidized molecule determined so far being 15-hydroxy-7oxodehydroabietic acid $[10,11]$. Although pimaranes are more stable, some studies also revealed their diminution during ageing $[6,12]$. This reduction has sometimes been related to the pimaranes polymerization; however, the resulting polymer has not yet been identified, leaving the pimaranes ageing paths unsolved.

Spectroscopic studies performed to date including Pyrolysis coupled to GC/MS (Py-GC/MS) [14-18], Fourier Transform Infrared (FTIR) Spectroscopy [19-25] and Raman Spectroscopy [2629] among other techniques [30] have been focused on the identification of the Pinus resin by determining its characteristic footprints. Nevertheless, a spectroscopic study of the ageing process is expected to give very valuable additional information since, unlike GC/MS, it can detect macromolecules and it doesn't require any sample treatment such as dissolving or derivatization, to identify how molecular species are organized and which reactions or interactions exist among them. One of the properties of FTIR spectroscopy is the low sensitivity and the difficult interpretation if the sample is mixed with any other material: working with a FTIR coupled to a microscope ( $\mu \mathrm{FTIR})$ and using a good sample preparation method can help to obtain good data which makes interpretation easier.

The aim of this research is to follow by FTIR spectroscopy the compositional changes, reactions and interactions between molecules occurring during natural ageing process of Pinus resins. As the verification of specific molecules is a crucial step, this research includes the study of chemical standards of the main compounds and complementary analysis with GC/MS following the analytical methods successfully used in literature [5-12].

Initially, chemical standards of the main components of Pinus resin have been analysed and band assignments have been proposed. Next, the first steps of natural ageing in both fresh resin and abietic acid itself (chief compound of Pinus resins) are monitored by FTIR, identifying the spectral features related to the process. Finally, long-term degraded samples have been studied, and for this having well-dated aged resins is essential. Old Pinus resins samples may be obtained from archaeological and artistic objects as it was a cheap easily found material all over Europe [32,33] and consequently widely used. Pinus resins can be found in varnishes and protective coatings (furniture, weapons...) applied over daily objects and artworks [34,35], also as adhesives to fill gaps and consolidate panels $[36,37]$.

\section{Materials and methods}

\section{Chemical reagents}

Abietic, dehydroabietic and isopimaric acids were purchased from Sigma A Idrich (ref. 101392305, ref. SMB00089 and MKBT3436V respectively) and their purity checked 
by GC/MS. 15-hydroxy-7-oxodehydroabietic acid was purchased from Chemfaces (ref. CFN97533).

Methanol from Sigma Aldrich (ref. 3460) and MethPrepll from Grace (ref. 18007) were used in the reactivity tests and chromatographic analysis. Acetic acid from Panreac (ref. 131008.1611) was used for acidification.

\section{Fresh resins samples}

The genus and species from all the natural resins studied were certified; subspecies and variants were not considered. Fresh resins were collected directly from the tree; resins of Pinus canariensis C.Sm. ex DC. and Pinus sylvestris L. were collected in March 2014 at Jardi Botànic de Barcelona, resins of Pinus halepensis Mill. and Pinus pinea L. in the coast of Tarragona (Catalonia). The resins were applied in thin film while the resin was still viscous and then were naturally aged for 16 months (from March 2014 to July 2015). One sample of each kind was aged in the open air (temperature range between 10 and $27^{\circ} \mathrm{C}$ ) but protected from direct sunlight and meteorological inclemency (wind, rain...) and the other was aged in a dark closed cupboard (temperature range between 20 to $25^{\circ} \mathrm{C}$ ).

\section{Aged resin samples}

Some aged resins were supplied by "Economic Botany Collection of the Royal Botanic Gardens, Kew", Richmond (Greater London, UK): Pinus nigra (ref. 28172, resin from Cyprus displayed at the Forestry Exhibition in Edinburgh, 1884), Pinus halepensis (ref. 79882, resin sold in the market in Syria, 2007) and Pinus sylvestris (ref. 28417, dated between 1850 and 1900). Other samples were extracted from the varnish of the $16^{\text {th }}$ century canvas entitled "Comte Borrell" by Filippo Ariosto and from the knot of the wooden frame of the panel no. 173 from the ceiling of Santa Maria de Paretdelgada Chapel (Selva de Mar, Catalonia) dated from the $14^{\text {th }}$ century.

\section{Instrumental}

FTIR measurements were taken in transmission mode using a Shimadzu IRAffinity ${ }^{-1}$ spectrometer with an AIM-8800 microscope and a MCT detector. Micro-fragments of the materials were squeezed into a diamond anvil cell to ensure the adequate thickness for analysis. The measurement conditions were: $4000-700 \mathrm{~cm}^{-1}$ interval, $4 \mathrm{~cm}^{-1}$ resolution, 256 scans and a $100 \times 100$ square micrometer spot. At least three spectra were measured and compared to each other to ensure the reproducibility of the data. All spectra shown are raw, neither baseline correction nor smooth procedures were applied to the spectra.

GC/MS analyses were performed with an Agilent Chromatograph (6850 model and HP-5MS column) coupled to an Agilent Mass Spectrometer (model 5975C). The samples were dissolved in $20 \mu \mathrm{l}$ of methanol, derivatized with $15 \mu \mathrm{l}$ of MethPrepll and heated at $66.6^{\circ} \mathrm{C}$ for 2 hours. Splitless injection was used with a non-linear heating ramp from 60 to $300^{\circ} \mathrm{C}$; the spectrometer temperature was fixed at $300^{\circ} \mathrm{C}$. Molecules were identified through comparison with the NIST database.

All figures have been generated with Grapher Golden Software (version 11.4.770). 


\section{Tests}

The esterification of Fig. 5 was done by adding an excess of MethPrepll and heating at $66.6^{\circ} \mathrm{C}$ for 2 hours. The acidification was done by adding an excess of acetic acid and heating for 2 hours, then it was left uncovered until the acid evaporated, about 1 hour.

The hydrolysis of acid anhydrides performed in Fig. 8 was done by adding an excess of water and heating for three hours, then it was left uncovered until water was evaporated, about 1 hour [38].

\section{Results and discussion}

\section{Reference materials}

The correct assignment of the Pinus resin infrared bands is fundamental for any further study. Consequently, abietic acid, dehydroabietic acid, 15-hydroxy-7-oxodehydroabietic acid and isopimaric acid were analyzed by IR spectroscopy and specific characteristic markers of the molecular structures were identified and band assignments proposed.

The IR spectrum corresponding to the abietic acid is shown in Fig. 1a. The bands at $3200 \mathrm{~cm}^{-1}$, 2648 and $2534 \mathrm{~cm}^{-1}$ correspond to the group $-\mathrm{COOH}$; the former to free $\mathrm{OH}$ (not the main one) and the last two to bonded $\mathrm{OH}$, the most common since in solid state the carboxylic groups tend to form dimers [39]. These last bands appear overlapped with overtones and combination bands of lower-frequency vibrations from the $\mathrm{COOH}$ group which also appears around 1550 [40]. The $\mathrm{C}-\mathrm{H}$ stretching absorption bands nearby $2900 \mathrm{~cm}^{-1}$ also show a complex shape due to the presence of $=\mathrm{CH},-\mathrm{CH}_{3},-\mathrm{CH}_{2}$ and $-\mathrm{CH}$ groups, where the $-\mathrm{CH}_{2}$ bands appear split due to the presence of conjugated $\mathrm{C}=\mathrm{C}$ bonds [41]. The narrow band at $1693 \mathrm{~cm}^{-1}$ belongs mostly to the stretching of $\mathrm{C}=\mathrm{O}$, but it also shows a shoulder at $1626 \mathrm{~cm}^{-1}$ and an overlapped band at $\sim 1670 \mathrm{~cm}^{-1}$ related to the presence of conjugated $\mathrm{C}=\mathrm{C}$ bonds. Finally, in the region under 1500 $\mathrm{cm}^{-1}$ a great number of bands are observed. The most intense at $1280 \mathrm{~cm}^{-1}$ corresponds to the $\mathrm{C}-\mathrm{O}$ deformation from the $-\mathrm{COOH}$ group and the peak at $891 \mathrm{~cm}^{-1}$ is related to the $\mathrm{C}-\mathrm{H}$ deformation out of plane of conjugated double bonds. [39, 41-45]

The infrared spectrum corresponding to dehydroabietic acid (Fig. 1b) is similar to those of abietic acid although it shows some minor differences (Fig. 1b). The band at about $3000 \mathrm{~cm}^{-1}$ corresponds to $\mathrm{C}-\mathrm{H}$ stretching, but unlike abietic acid, the $-\mathrm{CH}_{2}$ bands appear un-split because the conjugated $\mathrm{C}=\mathrm{C}$ bonds are now related to the aromatic group, which doesn't split the $-\mathrm{CH}_{2}$ bands. As in abietic acid, the bands around 3200 and $2600 \mathrm{~cm}^{-1}$ correspond to $\mathrm{O}-\mathrm{H}$ stretching, overtones and combined bands. The $1695 \mathrm{~cm}^{-1}$ band corresponds to the $\mathrm{C}=\mathrm{O}$ stretching belonging to $-\mathrm{COOH}$ group. Below $1500 \mathrm{~cm}^{-1}$, the band at $1498 \mathrm{~cm}^{-1}$ corresponds to the $=\mathrm{C}-\mathrm{H}$ stretching of the aromatic groups and the band at $819 \mathrm{~cm}^{-1}$ to the out of plane deformation of the aromatic $\mathrm{C}-\mathrm{H}$ group. Finally, the band at $891 \mathrm{~cm}^{-1}$ is not present as it is related to conjugated double bonds. $[41,45,46]$.

The 15-hydroxy-7-oxodehydroabietic acid is the most oxidized compound determined in aged resins so far. Its infrared spectrum (Fig. 1c) shows differences depending on how the $-\mathrm{OH}$ groups are bonded to $[41,45]$. This is clearly seen by comparing the spectrum corresponding to 
the commercial compound (Fig. 1c, black line) with the one obtained from the dried acid after dissolving it in methanol (Fig. 1c, grey line). The narrow band at $3532 \mathrm{~cm}^{-1}$ corresponds to free -OH groups; this band is more intense in the commercial compound but a new broad band around $3400 \mathrm{~cm}^{-1}$ corresponding to $-\mathrm{OH}$ groups with intermolecular bonds appears in the treated acid. Differences in the $-\mathrm{OH}$ structure also affect the $1700 \mathrm{~cm}^{-1}$ and $1200 \mathrm{~cm}^{-1}$ regions. The $1700 \mathrm{~cm}^{-1}$ band appears broader in the treated compound due to the presence of hydrogen bonds between hydroxyls and carboxylic acid groups. Owing to the intermolecular bonds created in the treated acid the $1271 \mathrm{~cm}^{-1}$ band decreases while the $1242 \mathrm{~cm}^{-1}$ band rises (non-bonded and bonded C-O stretching). Consequently, the detection of this molecule is problematic since different bands related with $-\mathrm{OH}$ are to be expected in its spectrum depending on the molecules to which it bonds; nevertheless, here it is proposed the rise of the $\sim 3400$ (O-H stretching of bonded hydroxyl group) and $\sim 1245 \mathrm{~cm}^{-1}$ (C-O deformation of bonded hydroxyl group) bands (Fig. 1c) as a markers of its presence. [41,45]

Finally, the spectrum corresponding to the isopimaric acid (Fig. 1d) is similar to those of the abietic and dehydroabietic acids. A complex band at about $3000 \mathrm{~cm}^{-1}$ consequence of the variable environment of the $-\mathrm{CH}_{3},-\mathrm{CH}_{2}$ and $-\mathrm{CH}$ groups is observed. Moreover, the characteristic $\mathrm{O}-\mathrm{H}$ stretching, overtones and combination bands at 3200 and $1600 \mathrm{~cm}^{-1}$ are also present. The functional group characteristic of the pimaranes is the $=\mathrm{CH}_{2}$ with bands at $1824 \mathrm{~cm}^{-1}$ (overtone of $=\mathrm{CH}_{2}$ ) and $910 \mathrm{~cm}^{-1}$ (C-H deformation out of the plane). [41,45]

\section{Fresh materials}

Fresh Pinus resin is made mainly of non-oxidized abietanes and a smaller portion of pimaranes the exact amount of each varying depending on the specie [47-53]. This can be observed in the infrared spectra displayed in Fig. 2: different specie resins show variations mainly in the intensities of the bands directly related to the precise amount of each compound present.

The main compound is abietic acid in all the cases (Fig. 2, red and black lines), due to the fast conversion of non-oxidized abietanes (palustric acid, neoabietic acid, laevopimaric acid...) to abietic acid in the resin. However, some differences between abietic acid and fresh resins spectra can be appreciated. The $\mathrm{C}-\mathrm{H}$ stretching absorption band shows the largest differences. The higher intensity of the $\mathrm{C}-\mathrm{H}$ stretching absorption band at $\sim 2930 \mathrm{~cm}^{-1}$ in some fresh resins can be explained by the higher proportion of the $-\mathrm{CH}_{2}$ groups compared to those of pure abietic acid. The un-split bands corresponding to the symmetric $\mathrm{C}-\mathrm{H}$ stretching is due to the lower proportion of $\mathrm{C}=\mathrm{C}$ bonds (absent in the pimaranes) in the resins. There are also some other additional bands in the fresh resins spectra due to the presence of other compounds in minor amounts. From this, it can be seen that 1182 and $1020 \mathrm{~cm}^{-1}$ bands can be found in all fresh resins spectra, so they can probably be related with common compounds. Band at 1182 $\mathrm{cm}^{-1}$ is proposed as a marker for non-oxidized abietanes or volatile compounds $\left(\left(\mathrm{CH}_{3}\right)_{2}-\mathrm{CH}-\mathrm{CH}\right.$ stretching) because in this frequency range we can find of that functional group $[41,45]$ and, as shown in the next section, it disappears during ageing. On the other hand, $1020 \mathrm{~cm}^{-1}$ band is proposed as a pimarane marker $\left(\mathrm{CH}_{2}=\mathrm{CH}\right.$ wagging) as in this frequency range we can find that functional group $[41,45]$ and this band remains during ageing.

\section{Ageing changes}


Fig. 3 shows the changes happening in fresh Pinus halepensis Mill. resin samples aged in open air and indirect daylight. The most important and significant changes occur in the 1695 and $\sim 1245 \mathrm{~cm}^{-1}$ bands; the latter associated with 15-hydroxy-7-oxo-dehydroabietic acid as indicated before and the former associated to the $\mathrm{C}=\mathrm{O}$ stretching group. Although the peak position and intensity of the $1695 \mathrm{~cm}^{-1}$ band is not affected by ageing (both non-oxidized and oxidized - $\mathrm{COOH}$ species are present in the resin), it broadens due to the presence of a shoulder at $1725 \mathrm{~cm}^{-1}$ probably related to the $\mathrm{C}=0$ stretching of the ketone group of the 7oxodehydroabietic and 15-hydroxy-7-oxo-dehydroabietic acids. The presence of the 1610 and $\sim 1500 \mathrm{~cm}^{-1}$ bands related to the aromatic groups agrees with the identification of those acids. Additionally, the broadening of the $1696 \mathrm{~cm}^{-1}$ band may also be related to the presence of hydrogen bonds from the $-\mathrm{OH}$ and $-\mathrm{COOH}$ groups and to a minor contribution from oxalates. Finally, the increase in the $1245 \mathrm{~cm}^{-1}$ band hides the presence of other bands related to the resin such as the $1280 \mathrm{~cm}^{-1}$ band.

Other changes observed are the broadening of the bands around 2650 and $2530 \mathrm{~cm}^{-1}$ which are explained by the increase in the chemical variability around the $-\mathrm{COOH}$ groups. The regions $1200-1100$ and $1050-800 \mathrm{~cm}^{-1}$ where skeletal vibrations appear, show an increased absorption which also can be related the formation of other types of molecules due to ageing.

Abietic acid was also aged similarly to study the oxidative process without the interference of pimaranes and the corresponding IR spectra are shown in Fig. 4. The initial processes fully agree with those of Pinus resin and, consequently, it can be concluded that the main changes observed in the Pinus resin spectra correspond to the oxidation of abietic acid.

As the $-\mathrm{COOH}$ and $-\mathrm{OH}$ band assignments are fundamental for this study, some chemical treatments were performed to a sample of naturally aged (3 months) Pinus pinea L. resin (Fig. 5a) in order to verify them. The first treatment consisted in the derivatization of the resin using MethPrepll to transform the $-\mathrm{COOH}$ groups into $-\mathrm{COOCH}_{3}$ (Fig $5 \mathrm{~b}$ ). It can be seen that bands related to $-\mathrm{COOH}$ groups decrease $\left(\mathrm{O}-\mathrm{H}\right.$ stretching at $\sim 3200$ and $\sim 2600 \mathrm{~cm}^{-1}, \mathrm{C}=\mathrm{O}$ stretching at $1695 \mathrm{~cm}^{-1}$ and $\mathrm{C}-\mathrm{O}$ deformation at $1280 \mathrm{~cm}^{-1}$ ) and some bands related to the $-\mathrm{COOCH}_{3}$, like the $\mathrm{C}=\mathrm{O}$ stretching at $1724 \mathrm{~cm}^{-1}$, appear. The second treatment consisted in an acidification with acetic acid followed by a derivatization with MethPrepll to convert the $-\mathrm{COOH}$ groups into $-\mathrm{COOCH}_{3}$ and the $-\mathrm{OH}$ groups into $-\mathrm{OCH}_{3}$. The spectrum is shown in Fig. $5 \mathrm{c}$ : It can be seen that bands related to $-\mathrm{COOH}$ and $-\mathrm{OH}$ groups $\left(\mathrm{O}-\mathrm{H}\right.$ stretching at $\sim 3400 \mathrm{~cm}^{-1}$ and $\mathrm{C}-\mathrm{O}$ deformation at $1250 \mathrm{~cm}^{-1}$ from $-\mathrm{OH}$ ) decrease and also the bands related to the $-\mathrm{COOCH}_{3}$ and $-\mathrm{OCH}_{3}$ appear.

Fig. 6 shows the IR spectra corresponding to the Pinus pinea L. and Pinus halepensis Mill. resins before and after the first ageing stages (16 months), both in darkness and open-air conditions. The small differences observed among the various fresh species can hardly be appreciated in the aged resins. This was not wholly unexpected as all abietanes evolve into the same oxidized form. The samples aged under different conditions (darkness and open-air) also show similar results. However, comparing the bands corresponding to the oxidized abietanes $(3400,1725$, 1606, 1500 and $1245 \mathrm{~cm}^{-1}$ ) for an equivalent ageing period, the samples kept in a dark environment appear less oxidized than those aged in open-air conditions. Consequently, open 
air accelerates the degradation process but the identified compounds are the same (at least the ones which can be detected by FTIR analysis).

It is also important to notice that the changes observed during natural ageing differ from those observed in artificial photo ageing [54].

\section{Ancient resins}

To identify the changes at advanced degradation stages we have to rely on the study of well dated ancient resins. However, the degradation degree depends not only on age but also on the storage environmental conditions, as it can be seen in Fig. 6 and in the literature $[55,56]$. In order to verify the chemical composition and in particular the presence of oxidized compounds, the resins were first analyzed by GC/MS.

According to GC/MS data (Fig. 7), the older resins show the higher concentration of oxidized compounds, i.e. a more advanced degradation. In the FTIR spectra, the bands related to the hydroxyl, ketone and aromatics groups which can be found only in the oxidized compounds (Fig. 7) increase. The bands associated to the hydroxyl groups appears at $\sim 3400 \mathrm{~cm}^{-1}(\mathrm{O}-\mathrm{H}$ stretching) and $\sim 1245 \mathrm{~cm}^{-1}$ (O-H deformation); those related to the ketones appears at $\sim 1725$ $\mathrm{cm}^{-1}$ ( $C=0$ stretching). Finally, those related to the aromatic $C=C$ stretching appears at 1606 , 1514 and $1496 \mathrm{~cm}^{-1}$ (the latter probably belonging to dehydroabietic acid). All these changes are also observed in other aged Pinus resin IR spectra found in the literature [54,57-59].

Nevertheless, the increased absorption observed between 1740 and $1800 \mathrm{~cm}^{-1}$ and also at about $1155 \mathrm{~cm}^{-1}$ (Fig. 7e) cannot be linked to the presence of a functional group of any related molecule. Here it is proposed that these bands be assigned to the acid anhydride groups formed by the reaction of two carboxylic acid groups from different molecules (abietanes or pimaranes), as they agree with the frequency range described for this group (C-O-C and C-C-O stretching) $[41,45]$. To confirm this hypothesis a treatment which consists in hydrolyzing the acid anhydride bonds was performed (experimental details have been explained in previous section): results are in Fig. 8. The GC/MS analysis (Fig 8a) shows that after the hydrolysis there is a higher concentration of pimaranes and other oxidized compounds, which can be explained because they were originally linked by acid anhydride bonds so they could not be detected by GC/MS in the first analysis. In the same way in FTIR spectra (Fig. 8b) the shoulder between 1740 and $1780 \mathrm{~cm}^{-1}$ can be observed before hydrolysis decreases: this could be explained because the acid anhydride bonds have been hydrolyzed so the related bands have diminished. The formation of acid anhydride bonds could also explain why pimaranes were not detected in aged samples by GC/MS. It also agrees with the results obtained by Size Exclusion Chromatography showing the presence of high molecular weight compounds in aged resins [57].

Finally, even in the most degraded materials the $\mathrm{O}-\mathrm{H}$ stretching band at $\sim 3400 \mathrm{~cm}^{-1}$ increases and the 1245 band is still present (Fig. 7). This suggests that there is no evidence of the reaction reported by other studies [60] between the hydroxyl group from 15-hydroxy-7-oxodehydroabietic acid and a carboxylic acid group from other molecules to form esters, so if they are formed are in such a low quantity that it is not possible to detect them by FTIR analysis. 
A summary of the processes happening during ageing is shown in Fig. 9 where specific IR markers for the identification of the various compounds produced during the degradation stages are also proposed.

\section{Conclusions}

A systematic study of the natural ageing of some Pinus resins and related compounds was performed by FTIR. The oxidative processes and molecular changes were identified giving the possibility of obtaining information about them in unknown samples. However, the limitations of FTIR technique must be kept in mind, namely the low sensitivity and the interpretation problems that arise when the spectra obtained have impurities and bands cannot be properly identified.

Results confirm the initial transformation of abietic acid into dehydroabietic acid and then into more oxidized species. At advanced stages of the transformation, reactions and interactions among molecules take place. On the one hand, the hydroxyl group of the 15-hydroxy-7-oxodehydroabietic acid stablishes intermolecular bonds. On the other hand, the reaction between two carboxylic acid groups from different molecules (abietanes or pimaranes) gives rise to the formation of acid anhydrides. This can explain in a more reliable way the decrease of the amount of pimaranes at the late stages of ageing than the polymerization between them. Moreover, no evidences have been found to confirm other reactions which have also been proposed, such as the esters formation.

Resins of the various species evolve into a similar molecular composition (oxidized abietanes and high molecular weight compounds). Different ageing conditions (open air and darkness) give the same results although at a different rate. Thus, it is difficult to establish a direct relationship between the age and the degradation of a sample.

IR bands related to the different stages of the transformation have been identified. The determination of both resins markers and degradation degree markers are essential since the identification of the resins is hampered by the degradation mechanisms happening from their exudation.

Finally, as abietanes can be found in other Pinaceae species, like Larix decidua Mill. or Abies alba Mill., these results can also be relevant for their study.

\section{Acknowledgements}

We acknowledge the financial support received for the development of this study from MINECO (Spain), grant MAT2013-41127-R and Generalitat de Catalunya, grant 2014SGR-581.

We would like to thank to Centre de Restauració de Bens Mobles de Catalunya (CRBMC) for their help with the chromatographic analysis and for supplying the artwork samples. Also we would like to thank David Bertran Chavarria curator of "Jardí Botànic de Barcelona" for supplying the fresh resin samples and the "Economic Botany Collection of the Royal Botanic Gardens, Kew", in London, for supplying dated ancient resins. 


\section{References}

[1] Richardson DM (2000) Ecology and Biogeography of Pinus. Cambridge University Press, Cambridge

[2] Belgacem, MN, Gandini A (2008) Monomers, Polymers and Composites from Renewable Resources. Elsevier, Oxford

[3] Fiebach K, Grimm D (2007) Ullmann's Encyclopedia of Industrial Chemistry, vol. Resins, Natural ( $7^{\text {th }}$ ed). Wiley, Weinheim

[4] Langenheim JH (2003) Plant Resins: Chemistry, Evolution, Ecology, and Ethnobotany.

Timber Press, Cambridge

[5] Mills JS, White R (1999) Organic Chemistry of Museum Objects. Butterworth-Heinemann. New York

[6] Mills JS, White R (1977) Stud Conserv 22(1):12-31

[7] Colombini MP, Modugno F (2009) Organic Mass Spectrometry in Art and Archaeology. John Wiley \& Sons, Pisa

[8] Pastorova II, van der Berg KJ, Boon JJ, Verhoeven JW (1997) J Anal Appl Pyrol 43:41-57

[9] Osete-Cortina L, Doménech-Carbó MT, Mateo-Castro R, Gimeno-Adelantado JV, Bosch-

Reig F (2004) J Chromatogr A, 1024:187-194

[10] Berg KJ, Boon JJ, Pastorova II, Spetter LF (2000) J Mass Spectrom 35(4):512-533

[11] Steigenberger G, Herm C (2011) Anal Bioanal Chem 401(6):1771-84

[12] Abdel-Ghani M, Edwards HGM, Stern B, Janaway R (2009) Spectrochim Acta Part A 73:566-575 [13]

Chiavari G, Fabbri D, Prati S (2002) Chromatographia, 55(9-10):611-616

[14] Osete-Cortina L, Doménech-Carbó MT (2005) J Chromatogr A 18,1065(2):265-278

[15] Anderson KB, Winans RE (1991) Anal Chem 63:2901-2908

[16] Osete-Cortina L, Domenech-Carbo MT (2005) J Chromatogr A, 1065:265-278

[17] Prati S, Smith S, Chiavari G (2004) Chromatographia, 59, 227-231

[18] Osete-Cortina L, Doménech-Carbó MT (2006) J Anal Appl Pyrolysis 76:144-153

[19] Derrick MR, Stulik D, Landry JM (1999) Infrared Spectroscopy in Conservation Science. The Getty Conservation Institute, Los Angeles

[20] Beltran V, Salvadó N, Butí S, Cinque G (2015) Microchem J 118:115-123

[21] Font J, Salvadó N, Butí S, Enrich J (2007) Anal Chim Acta 598(1):119-127

[22] Bertrand L, Robinet L, Cohen SX, Sandt C, Le Hô AS, Soulier B, Lattuati-Derieux A, Echard JP (2011) Anal Bioanal Chem 399(9):3025-3032

[23] Robinson N, Evershed RP, Higgs WJ, Jerman K, Eglinton G (1987) Analyst 112:637-644

[24] Derrick M (1989) JAIC, 28,1:43-56

[25] Derrick M, Stulik DC, Landry JM, Bouffard SP (1992) JAIC, 31,2:225-236

[26] Daher C, Paris C, Le Hô A, Bellot-Gurlet L, Échard J (2010) J Raman Spectrosc 41(11):14941499

[27] Brody RH, Edwards HGM, Pollard M (2002) Biopolymers 67(2):129-41

[28] Vandenabeele P, Wehling B, Moens L, Edwards H, De Reu M, Van Hooydonk G (2000) Anal Chim Acta 407:261-274

[29] Prati S, Sciutto G, Mazzeo R, Torri C, Fabbri D (2011) Anal Bioanal Chem 399:3081-3091

[30] Doménech-Carbó MT (2008) Anal Chim Acta 621(2):109-139

[31] Scalarone D, van der Horst J, Boon JJ, Chiantore O (2003) J Mass Spectrom, 38:607-617

[32] European forest genetic resources programme . Accessed 14/01/2015

[33] Merrifield MP (1999) Medieval and Renaissance Treatises on the Arts of Painting: Original Texts with English Translations. Dover Publications, Inc., New York 
[34] Eastlake CL (2001) Methods and Materials of Painting of the Great Schools and Masters. Dover Publications Inc., New York

[35] Smith CS, Hawthorne JG (1974) Mappae Clavicula: A Little Key to the World of Medieval Techniques. American Philosophical Society, Philadelphia

[36] Thornton J (1998) J Am Inst Conserv 37(1):3-22

[37] Dardes K, Rothe A (1998) The Structural Conservation of Panel Paintings: Proceedings of a Symposium at the J. Paul Getty Museum, 24-28 April 1995. Getty Conservation Institute, Los

Angeles

[38] Jones R (2005) Comprehensive organic functional groups transformations II (vol. 5 Carbon with two heteroatoms with at least one carbon-to-heteroatom multiple link). Elsevier, Cambridge

[39] Flett M St C (1951) J Chem Soc 962-967

[40] Bratoz S, Hadzi D, Sheppard N (1956) Spectrochim Acta 8:249-281

[41] Bellamy LJ (1975) The Infra-red Spectra of Complex Molecules. Springer, London

[42] Blout ER, Fields M, Karplus R (1948) J Am Chem Soc 70(1):194-198

[43] Hadzi D, Sheppard N (1953) P R Soc A 216:247-266

[44] Hadzi D, Pintar M (1958) Spectrochim Acta 12:162-188

[45] Lin-Vien D, Colthup NB, Fateley WG, Grasselli JG (1991) The Handbook of Infrared and

Raman Characteristic Frequencies of Organic Molecules. Academic Press, London

[46] Katritzky AR, Phil D (1959) Q Rev Chem Soc 13:353-373

[47] Arrabal C, Cortijo M, Fernandez de Simon B, Garcia Vallejo MC, Cadahía E (2005) Biochem Syst Ecol 33:1007-1016

[48] Arrabal C, Cortijo M, Fernández de Simón B, García-Vallejo MC, Cadahía E (2002)

Holzforschung 56(3):261-266

[49] Rezzi S, Bighelli A, Castola V, Casanova J (2005) Ind Crop Prod 21(1):71-79

[50] Mosini V, Samperi, R (1985) Phytochemistry 24(4):859-861

[51] Joye N M Jr, Lawrence R V (1967) J Chem Eng Data 12(2):279-282

[52] Gref R (1987) Eur J of Forest Pathol 17(4-5):227-230

[53] Gören AC, Bilsel G, Öztürk AH, Topçu G (2010) Natural Product Communications 5, 11:1729-1732

[54] Azémard C, Vieillescazes C, Ménager M (2014) Microchem J 112:137-149

[55] Doménech-Carbó MT, Osete-Cortina L, de la Cruz Cañizares J, Bolívar-Galiano F, RomeroNoguera J, Fernández-Vivas MA, Martín-Sánchez I. (2006) Anal Bioanal Chem 385(7):1265-80

[56] Romero-Noguera J, Bolívar-Galiano FC, Ramos-López JM, Fernández-Vivas MA, MartínSánchez I. (2008) Biodeterioration \& Biodegradation 62 (4): 427-433

[57] Scalarone D, Lazzari M, Chiantore O (2002) J Anal Appl Pyrol 64:345-361

[58] Ménager M, Azémard C, Vieillescazes C (2014) Microchem J (114):32-41

[59] Ménager M, Perraud A, Vieillescazes C (2012) Archéosciences 37:7-17

[60] Tirat S, Deganod I, Echard JP, Lattuati-Derieux A, Lluveras-Tenorio A, Marie A, Serfaty S, Le Huerou JY (2016) Microchem J 126:200-213 

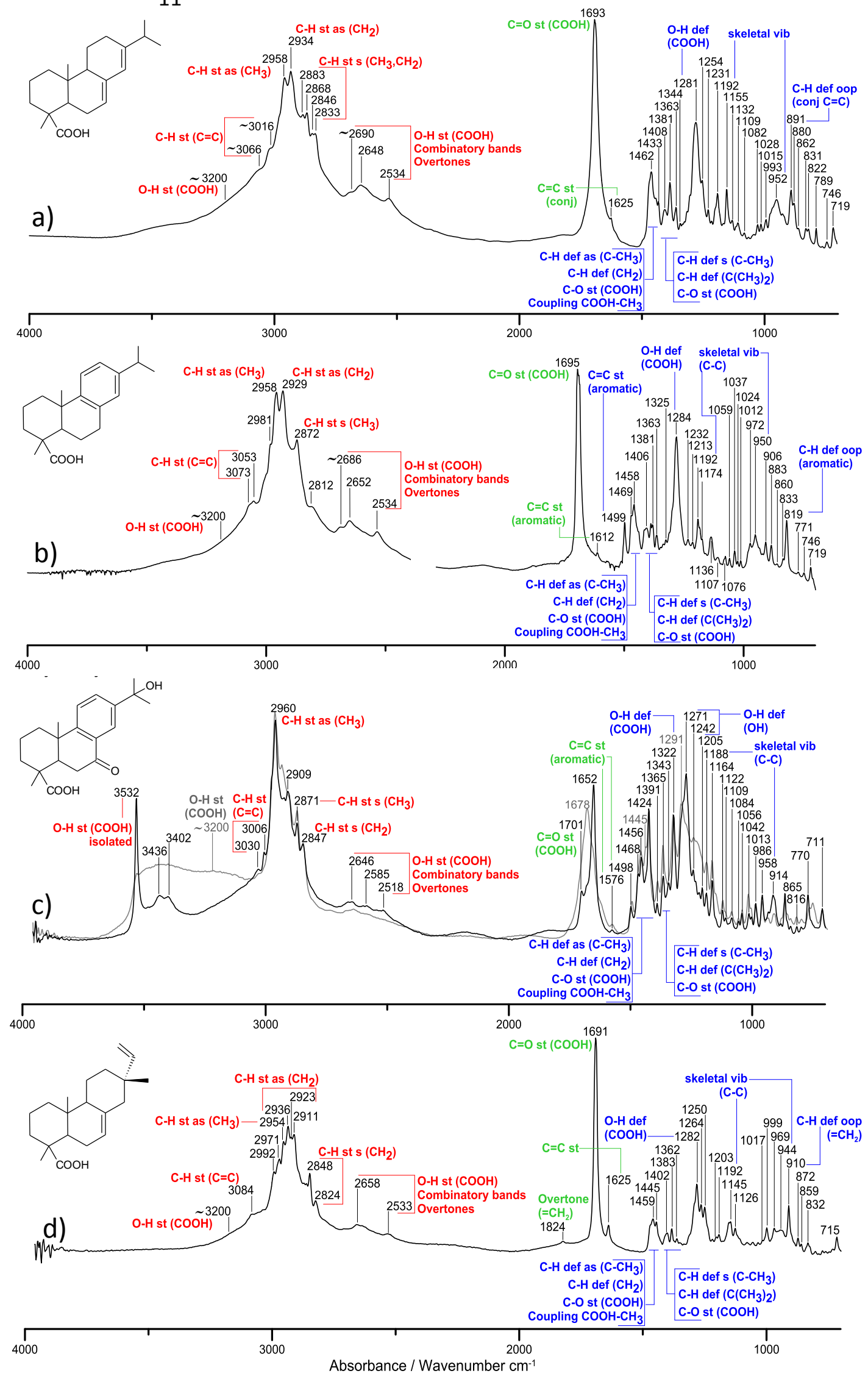

Fig. 1 Infrared spectra from a) abietic acid, b) dehydroabietic acid, c) 15-hydroxy-7oxodehydroabietic acid (black line corresponds to the pure compound, the grey line to the compound after dissolving it in methanol) d) isopimaric acid. 


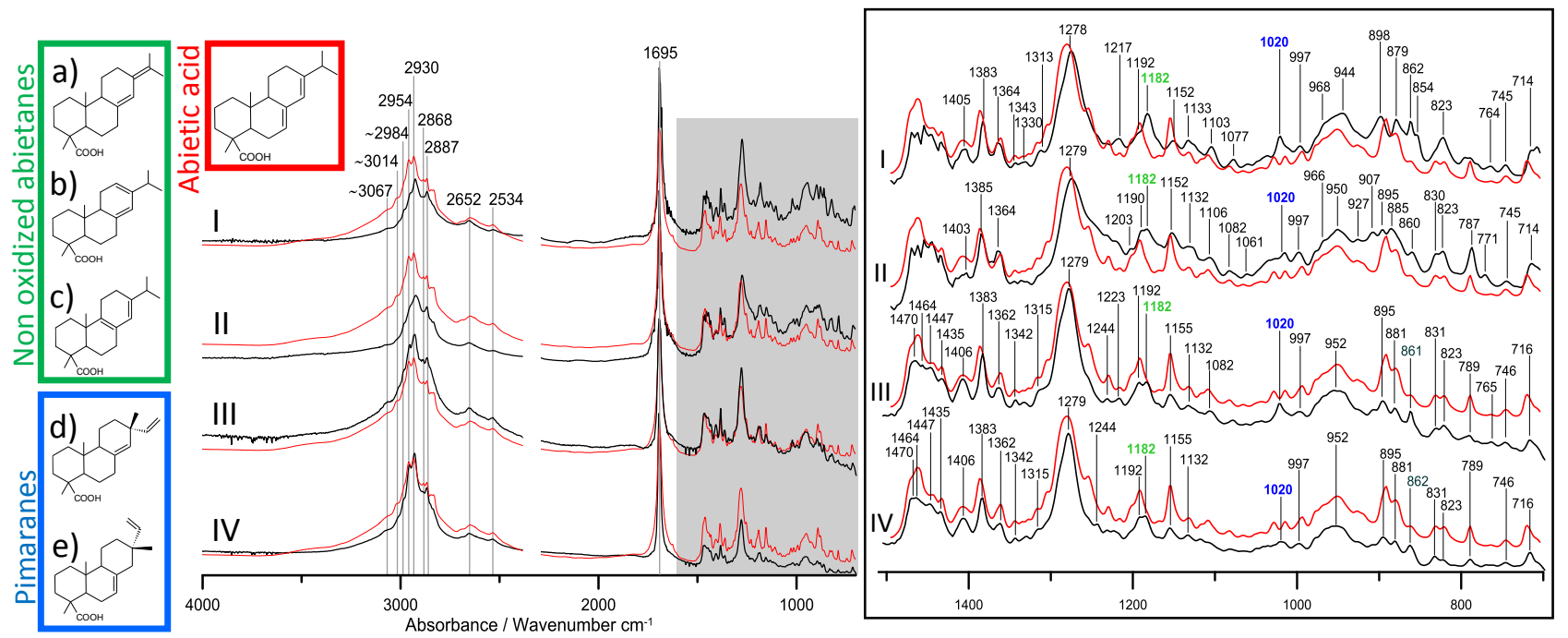

Fig. 2 Comparison between the infrared spectra of abietic acid (red line) and various fresh Pinus resins (black line); I: Pinus canariensis C.Sm. ex DC., II: Pinus sylvestris L., III: Pinus pinea L., IV: Pinus halepensis Mill. An enlargement of the $1500-700 \mathrm{~cm}^{-1}$ region is shown at the right. Marked in green the wavenumbers proposed for the identification of abietanes and in blue for the pimaranes. The molecules corresponding to some of the abietanes (a: neoabietic acid, $b$ : laevopimaric acid, c: palustric acid) and pimaranes (d: sandaracopimaric acid, e: isopimaric acid) are shown at the left. 
a)<smiles>CC(C)c1ccc2c(c1)C(=O)CC1CCCCC21C(C)C</smiles><smiles>CC(O)(O)c1ccc2c(c1)CCCCC21CCCCO1</smiles>
c)

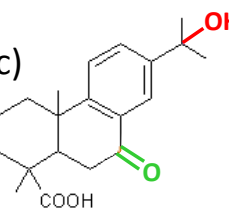

C-H st as $\left(\mathrm{CH}_{2}\right)$ 15 months 15 months

14 months mpminmm 11 months 8 months 4 months 2 months 1 month 1 week Fresh

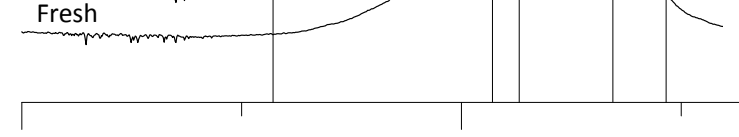

4000

3000

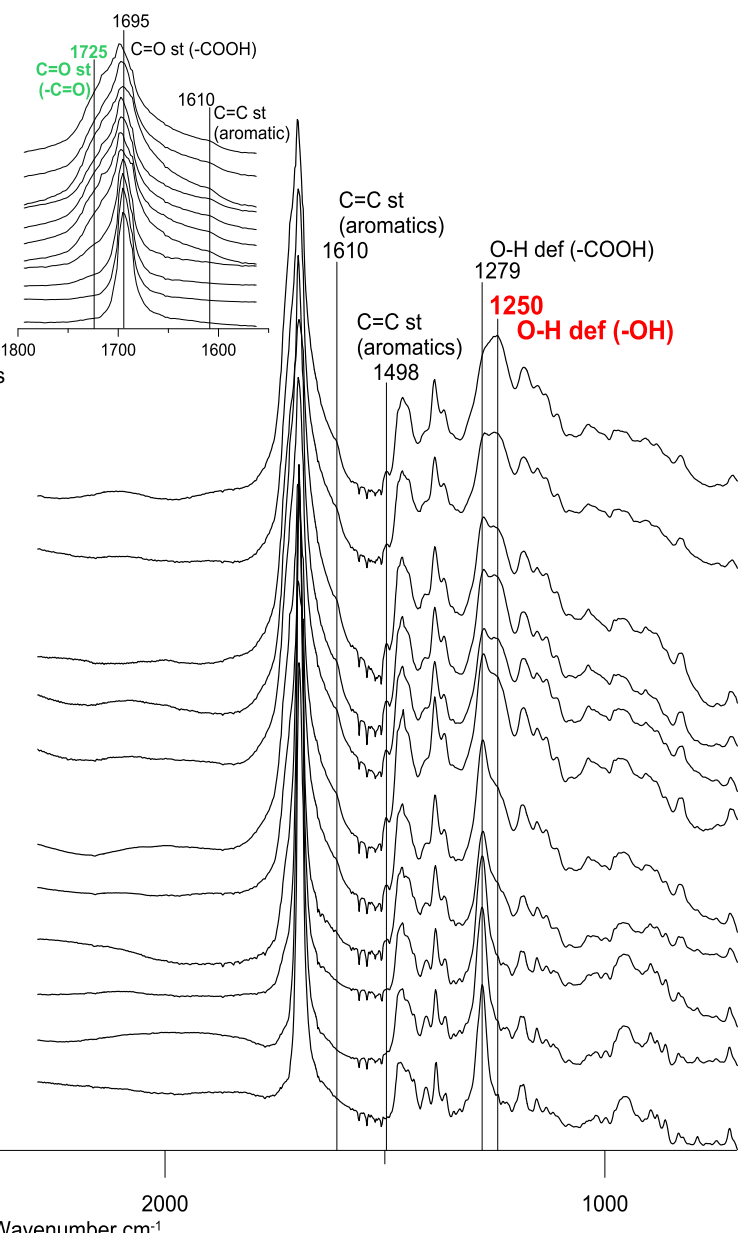

Fig. 3 From top to bottom infrared spectra corresponding to the first 16 months of the ageing of the Pinus halepensis Mill. resin. A magnification of the carbonyl band is shown at the middle-top. The molecules corresponding to the main oxidized abietanes are shown at the left (a: 7-oxodehydroabietic acid, b: 15-hydroxydehydroabietic acid, c: 15-hydroxy-7oxodehydroabietic acid). Functional groups are in the same color as their proposed specific markers. 


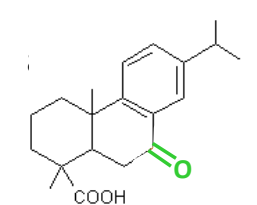

b)<smiles>CC(C)(O)c1ccc2c(c1)CCC1C2CCC1(C)O</smiles>

c)<smiles>CCCC1CC(=O)c2cc(C(C)(C)O)ccc2C1CC</smiles>

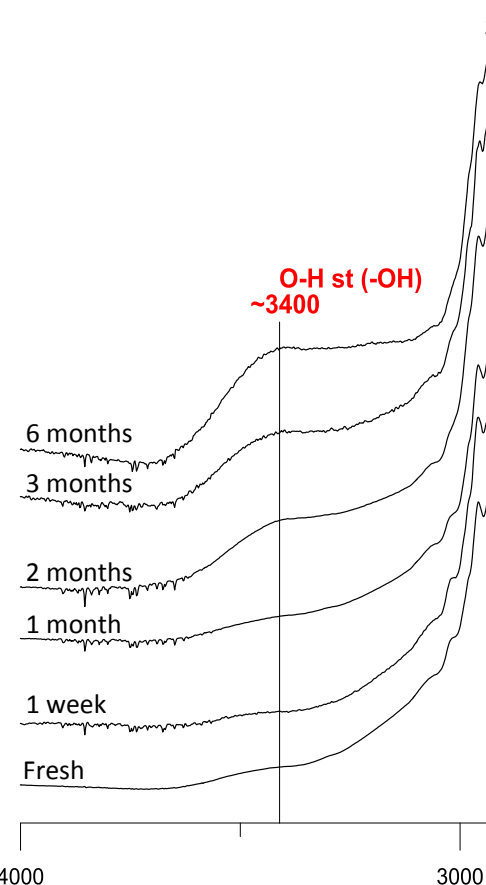

3000
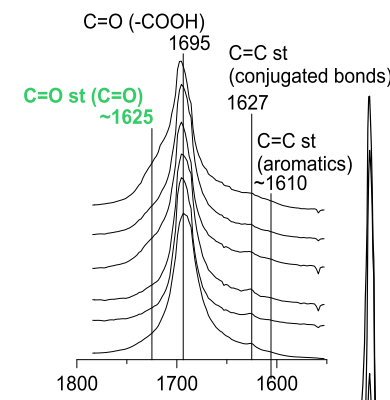

$\mathrm{C}=\mathrm{C}$ st $\quad \mathrm{O}-\mathrm{H}$ def $(-\mathrm{COOH})$

(aromatics)

1610

1279

$\mathrm{C}=\mathrm{C}$ st $\quad 1250$ - $\mathrm{H}$ def $(-\mathrm{OH})$

(aromatics)

1500

Combinatory bands

2648

2534

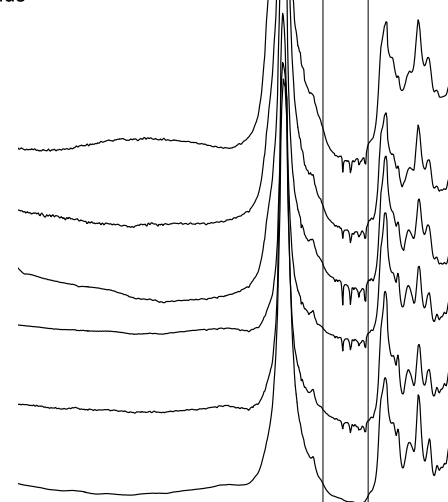

2000

Fig. 4 From top to bottom infrared spectra corresponding to the first 6 months of the ageing of the abietic acid. A magnification of the carbonyl band is shown at the middle-top. The molecules corresponding to some of the oxidized abietanes are shown at the left (a: 7oxodehydroabietic acid, b: 15-hydroxydehydroabietic acid and c: 15-hydroxy-7oxodehydroabietic acid). Functional groups are in the same color as their proposed specific markers. 


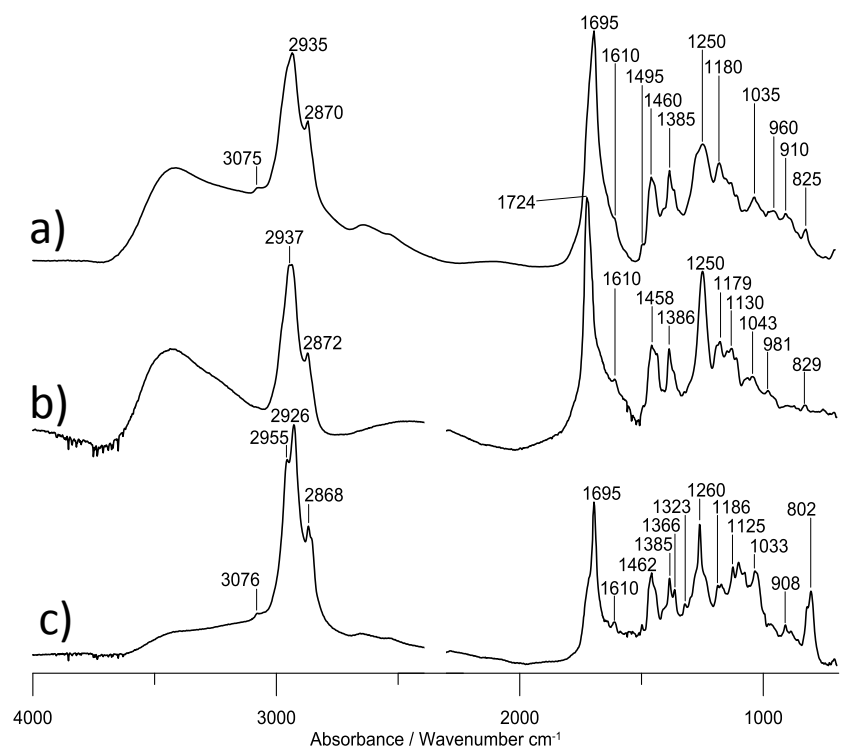

Fig. 5 Infrared spectra of a) untreated Pinus Pinea L. b) Pinus Pinea L. after derivatization with MethPrepll c) Pinus Pinea L. after acidification with acetic acid and derivatization with MethPrepll. 


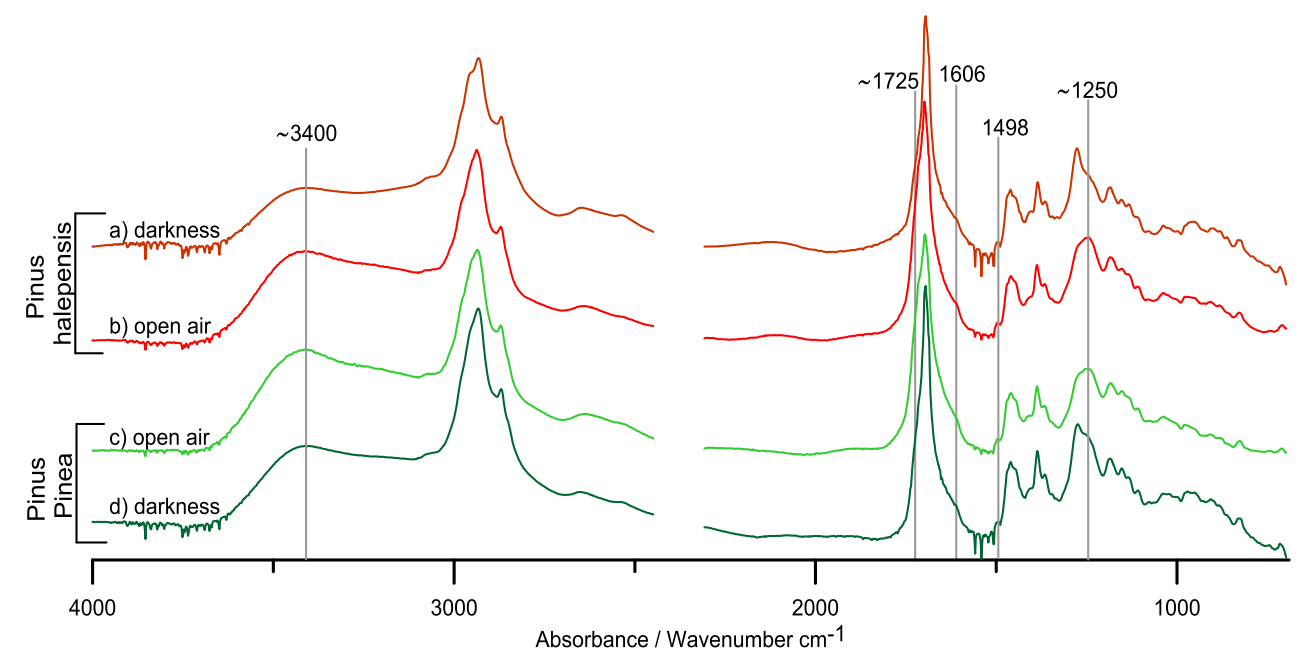

Fig.6 Comparison between infrared spectra from different Pinus resins aged under diverse conditions. a: Pinus halepensis Mill. aged in darkness, b: Pinus halepensis Mill. aged resin in open air and indirect daylight, c: Pinus pinea L. aged in open air and indirect daylight,, d: Pinus pinea L. aged in darkness. Marked wavenumbers belong to the bands proposed for the identification of oxidized abietanes. 

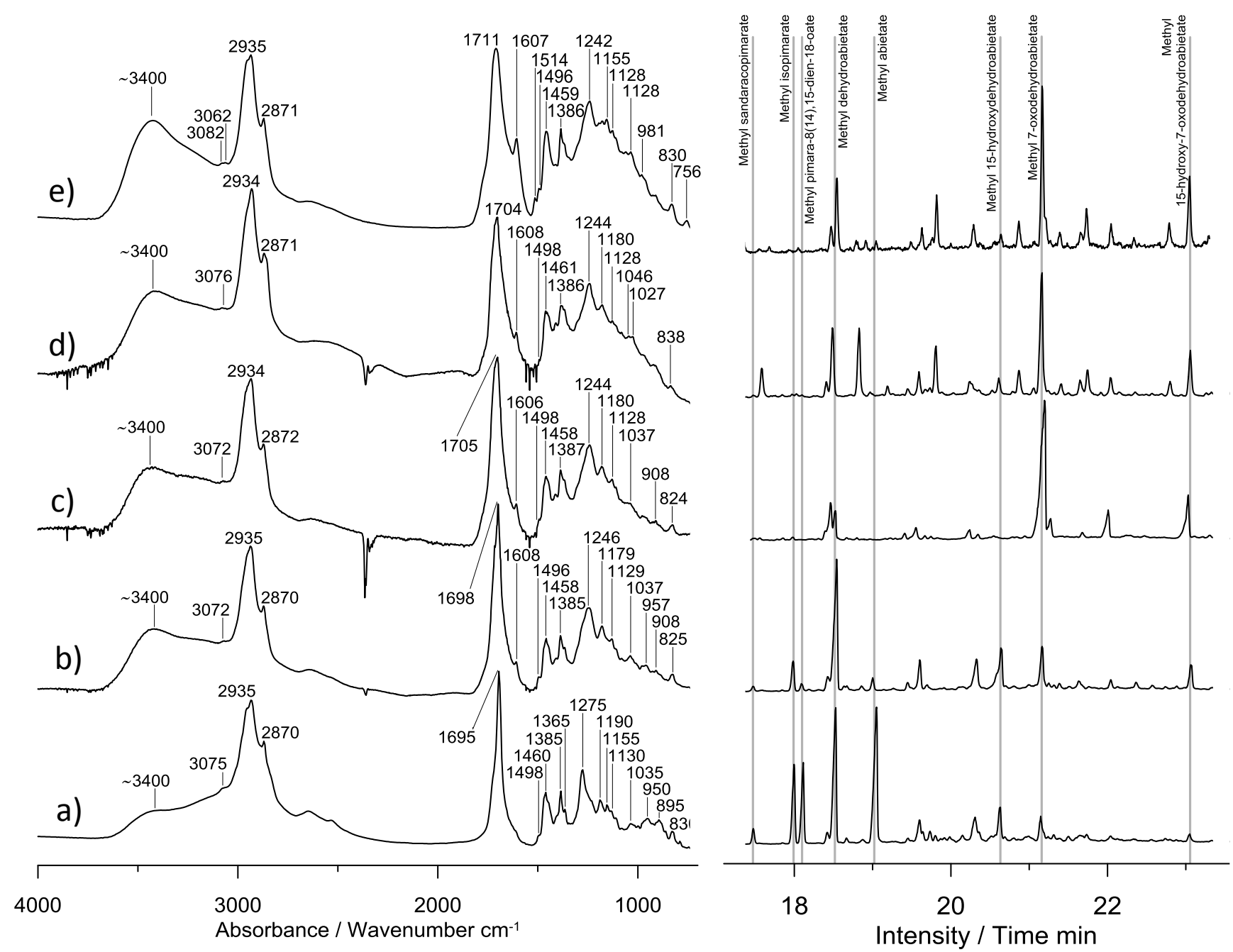

Fig. 7 FTIR spectra (left) and GC/MS (right) from aged natural resins: a) Pinus halepensis (dated in 2007) b) Pinus sylvestris (unknown date) c) Pinus nigra (dated in 1884). Other historical samples d) varnish from a $16^{\text {th }}$ century canvas e) resin from a $14^{\text {th }}$ century wooden support. 


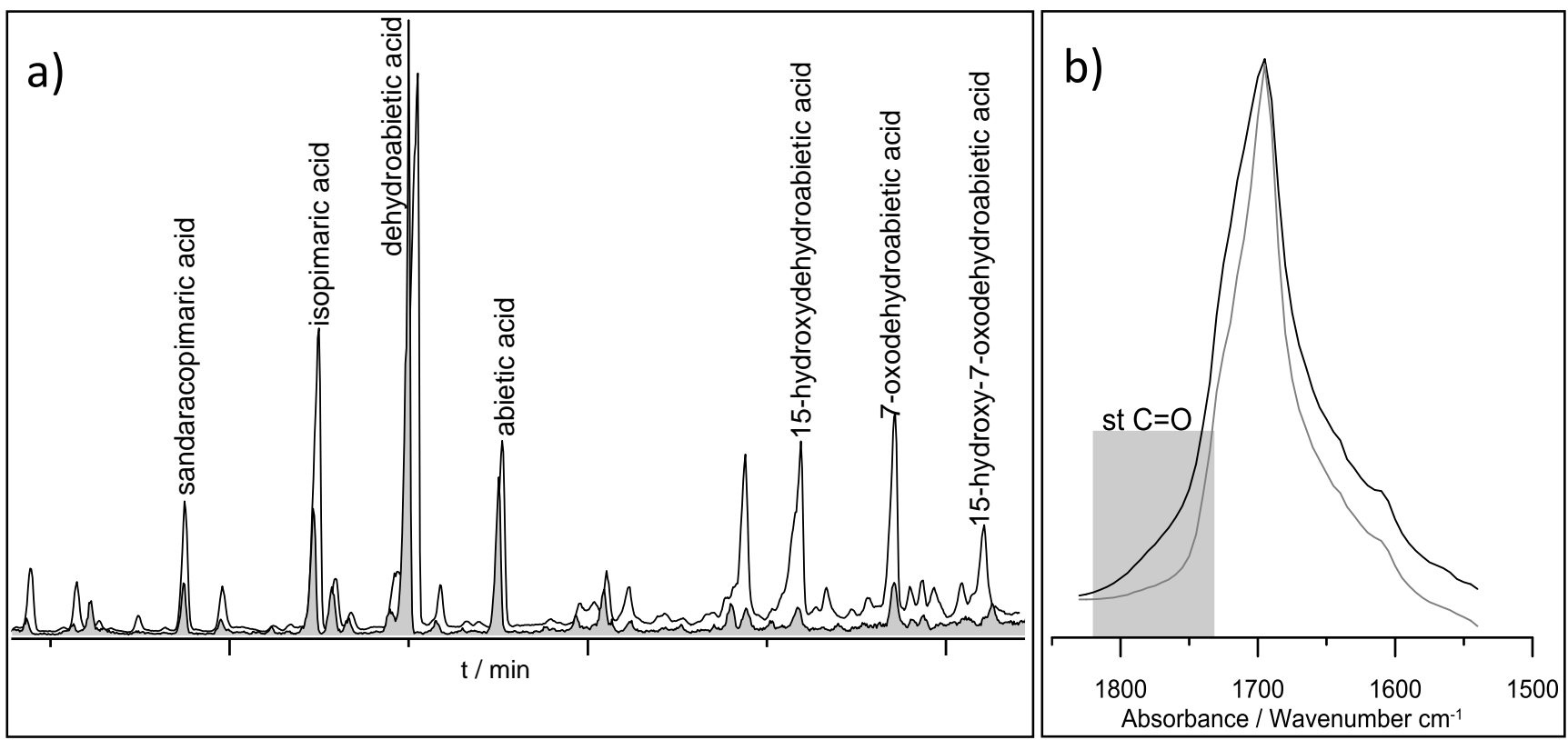

Fig. 8 Pinus pinea L. resin sample before and after the hydrolyzation. a) GC/MS analysis: original sample in grey and hydrolyzated sample in white b) FTIR spectra: black line is for original sample and grey line for hydrolyzed sample; grey area tags the region of $\mathrm{C}=\mathrm{O}$ stretching from acid anhydrides. 


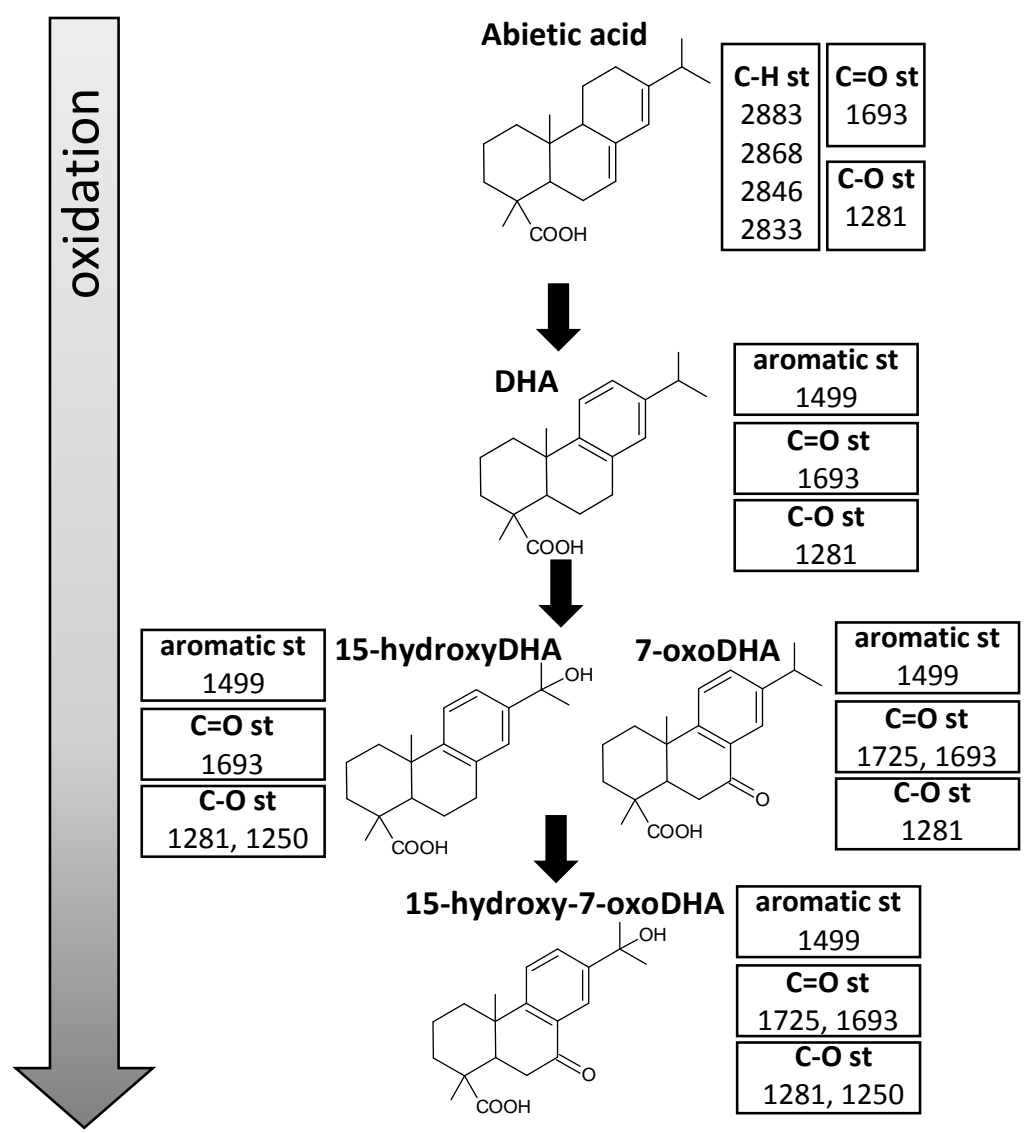

Fig. 9 Synopsis of the proposed specific markers in the infrared absorption spectra (numbers correspond to the wavenumbers in $\mathrm{cm}^{-1}$ ) 